\title{
ESTABLISHING RELATIONSHIP BETWEEN FACTORS AFFECTING BUILDING DEFECTS AND BUILDING CONDITION
}

\author{
Syamilah Yacob*1, Azlan Shah Ali², Cheong Peng Au-Yong ${ }^{3}$ \\ ${ }^{1}$ Public Work Department \& Ph.D. Candidate, University of Malaya, Kuala Lumpur \\ ${ }^{2,3}$ Department of Building Surveying, University of Malaya, Kuala Lumpur \\ E-mail: "syamilah75@gmail.com, asafab@um.edu.my, auyongcp@um.edu.my
}

\begin{abstract}
Defects and damage to the building are defined as the failure of the ability of the building to deliver services as expected. Inefficiency in handling defects or damage buildings systematically have to cause various effects and negative impact to users and is also the owner of the building. A total of 300 school buildings has been chosen for this study to identify the factors contribute to the building defects and to identify the condition of the buildings. The purpose of this paper is to establish the relationship between factors affecting, defects and building condition. The data is collected from through secondary reports from archive document of Public Work Department (PWD) Malaysia. A semi structure interview was conducted to confirm the common factors contribute to the defects especially for building in Malaysia. The findings show the 7 factors contribute a significant relationship with building condition of the school building such as maintenance, waterproofing, vandalism, lack of supervision, cleaning, user and the chemical agent. Result also shows found that 16 schools in good condition, 218 schools in average condition, 65 schools in critical condition and 1 school in very critical condition.
\end{abstract}

Keywords : Factors Defect, Building Defects, Building Condition, School Building, Malaysia

\section{INTRODUCTION}

In principles, the building should secure and protect the occupant from various weather conditions. Especially for the building element and services in the building. It should serviceable to suit the facilities in the buildings. So that to ensure the building safe and in a long term quality, the factors that caused the defects should be prevented. A defect is a building flaw and common problems in buildings. Building defects are one of the major building's problems that significantly needed attention (Bakri and Mydin et al., 2013). Cobbinnah (2010), mentioned that defects may result in extensive and avoidable damage to the building. A defect can define as element or building does not meet its expected performance criteria or loses its serviceability. According to the British Standard Code of Practice, BS 3811, (1984) defined defects as deterioration of building features and services to unsatisfactory quality levels of the requirement of users. Building defects can occur to any building without considering their age, type of construction and used of the buildings. As in Building Maintenance Guideline (The Government of Hong Kong Special Administrative Region, HKSAR, 2002) stated that defects can occur in various form to a different extent in all types of buildings irrespective of age. Inabilities in handling those building defects systematically provided negative impact to users and building owners as well.

Many types of research conducted and found that defects can be attributed to various factors. According to Ramly (2006), defects in the building are the problem faced by most of the building regardless of building construction techniques or age but it depends on to the causes and the factors causing the occurrence of the defects. The past decade had been discussed the defect factors and more attention needs to address the issues. This study will identify the factors contribute to the building defects and assessing the condition of the school building in Malaysia based on content analysis of PWD's report. The study is important to investigate the contribution 
defect factors in order to create a safe building (Low, 2001). The result of findings will discuss the relationship between factors affecting building defects and building condition. For this purpose, the theory of the association between factors and its condition was assessed.

The condition of public school in Malaysia is in poor condition. According to Ahluwalia (2008), reported that the school and educational buildings was the largest infrastructure sectors and were built more than 45 years old and need for extra care. Mydin et al. (2014) concluded that school buildings vastly exposed to building defects and physically affect the building. Previous research has shown that the highest number of building own by the government in Malaysia was school building and it was audited and reported in poor condition (MySPATA report, 2011; Ali, 2013; Yong, 2015; IKRAM Report of Overall Trend Assessment \& Analysis Report, 2011). Mydin et al (2014) reported that there are numerous defects most arise and being reported officially by mass media is educational buildings. While Mahli, (2012) stated that public school in Malaysia maintained in reactive mode.

\section{LITERATURE REVIEW}

\subsection{Common Building Defects}

Building defects can lead to many building problems (Mydin, 2012). According to Ahzahar et.al (2011) cited from Webster's Dictionary, describes the term of defects briefly as imperfection; fault; a blemish or deficiency. According to author David (1997), defined that defect is nonconformity of a component with a standard or specified characteristic. Research by Khalid (2012), reported that defects can be referred to fault on something that detract from perfection, whilst building damage can be seen when any structure, material, equipment and also element of the building was not fully functional. A defect is a shortfall in performance occurring at any time in the life of the product, element or building in which it occurs (BRE digest 286) or defect is interpreted as a fault in an element, material or component of a building.

Defects can occur at construction or during the handling over or occupancy stages. Studies by Chong (2005), have found that defects found during construction and occupancy were usually different even the defects had similar descriptions. The defects had different roots and were of the different nature. The author Chong (2005) also mentioned that building defects often appear after 2 years of the first age of the building or after occupancy. While building defects that occur after 6 or 7 years considered the effects of the adoption. Besides defects can also occur and looks over a period longer that cannot be estimated.

Most of the government buildings are faced with problems such as "cracking, staining/discoloration, sealant failures, efflorescence, rising dampness/water penetration, corrosion, buckling/deflection, tile/plaster delaminating" which have resulted due to poor building materials and workmanship (Shittu, et al., 2013). According to Hermawan (2008) defects defined imperfection; blemish; fault due to lack of design, manufacturing process or improper installation of material and identified and rank the defects according to most common defects such as blemishes, corrosion, damage of exterior surface, dampness, peeling paint, roof defects, cracking, etc. Mydin et al (2014), reported that the common defects such as peeling paint, dampness, discoloration, timber decay, etc were identified in his study. The study by Talib et al. (2014), reported that 5 major factors of building defect were ranked according to most significant factors which are a lack of maintenance, overlooked site condition, moisture problem, defective material and environmental condition. Agyekum (2016) from his studies concluded that it is very clear a number of studies have been conducted worldwide regarding common building defects, most in Malaysia.

\subsection{Factors Contribute to Building Defects}

The building problems such as defects is due to numerous main factors (Mydin, 2014). The past decade had been discussed about the defects factors and more attention need to address to overcome the issues. According to Ramly (2004), defects in the building are the problem faced by most of the building and it depends to the causes and the factors causing the occurrence of the defects. There are various factors that contribute to the building defect or deterioration. Several studies in the literature reporting that there are various factors contribute to the building defects. Previous studies by Talib et al. (2014), reported that the factors affecting the building defects according to highest to low rank such as lack of building maintenance, overlooked site condition, defective material, ageing of building, poor quality control, lack of training, lack of motivation, poor communication, environmental conditions and moisture problem. Mydin et.al (2014), in his study, identified building age, 
maintenance, poor workmanship and insufficient awareness as contribution factors to building defects. The major contributing causes of defects based on the level of importance are low quality of material, poor workmanship, weakness in the design and lack of awareness by occupants (Awol, 2016).

Furthermore Ahzahar et.al (2011) concluded that building failure and defect influenced by climate conditions, building location, the material of construction, type of building and functional changes, building maintenance, design fault, corruption and lack of supervision. Olagunju (2012), also through his studies mentioned that there are eight factors were identified to be significant to a physical condition of public buildings. The author Kian (2001), identified four factors contribute to building defects such as the action of load underestimated at design and construction stage, insufficient knowledge on construction /fixing of building element/component, failure to carry out necessary maintenance or incorrect identification of the cause of defect and failure joint element.

According to Shittu (2013) defects due to poor building materials and workmanship. Hermawan (2013), stated that fault due to lack of design, manufacturing process or improper installation of material are the factors contribute to building defects. While Ahluwalia (2008) in her study identified eight defect factors affecting the building condition such as the type of building, facility condition, demographic factors, age or major year of the renovation of the building, size, external and internal conditions, advance in information technology and maintenance frequency. Defects are categorized by their consequences. Those caused defects are different according to the type of building, location, and user of the building.

Based on research, a total of 40 factors were found in the literature which caused the building defect can be summarize in Table 1. The table shown that a total of 40 factors found caused the building defects.

Table 1: The factors contribute to the Building Defects

\begin{tabular}{cccc}
\hline No. & & Factors & \\
\hline $\mathbf{1}$ & Age & 21 & Lack of supervision \\
\hline $\mathbf{2}$ & Atmospheric & 22 & Maintenance \\
\hline $\mathbf{3}$ & Biological Agent & 23 & Material \\
\hline $\mathbf{4}$ & Building Elevation & 24 & Mechanical Agent \\
\hline $\mathbf{5}$ & Building Location & 25 & Moisture \\
\hline $\mathbf{6}$ & Building Ownership & 26 & Operation and installation \\
\hline $\mathbf{7}$ & Building Size & 27 & Soil Impact \\
\hline $\mathbf{8}$ & Chemical & 28 & Specifications \\
\hline $\mathbf{9}$ & Climatic Condition & 29 & Structural \\
\hline $\mathbf{1 0}$ & Condensation & 30 & Thermal Agent \\
\hline $\mathbf{1 1}$ & Construction & 31 & Type of Building \\
\hline $\mathbf{1 2}$ & Design & 32 & Usage \\
\hline $\mathbf{1 3}$ & Detailing & 33 & User \\
\hline $\mathbf{1 4}$ & Drawing & 34 & Vandalism \\
\hline $\mathbf{1 5}$ & Electromagnetic Agent & 35 & Ventilation \\
\hline $\mathbf{1 6}$ & Faulty Systems & 36 & Waterproofing \\
\hline $\mathbf{1 7}$ & Fire & 37 & Wear and tear \\
\hline $\mathbf{1 8}$ & Human & 38 & Weather \\
\hline $\mathbf{1 9}$ & Lack of knowledge & 40 & Workmanship \\
\hline & & & \\
\hline $\mathbf{2 0}$ & & 29 & \\
\hline
\end{tabular}




\subsection{Building Condition Assessment (BCA)}

Building performance can be measured in many ways, the most common being condition. According to Abbot (2007), building condition reflects the physical state of the buildings hence its performance. According to Straub (2009), condition assessment is a tool for assessing the technical performance of the properties to long-term maintenance expectations. Meanwhile research by Kaiser (1993), condition assessment is a process for inspecting and reporting the physical condition and functional performance of building and infrastructure systems and components. The aim of Building condition survey is the important stage to provide adequate information for appropriate repair work of the building to control defects and preserve the building (Johar et. Al, 2013; Ahmad, 2004).

Several studies by (Rugless,1993; DfES, 1993; and Ahluwalia, 2008) have revealed that building condition assessment is a tool to provide a systematic a process for getting information, a systematically evaluating a building condition in order to project repair, renewal, or replacement needs that will preserve their ability to support the mission or activities. So that the assessment of building condition is very important to supports decision making and it is also critical to the management in achieving the service standards for maintenance (Syamilah, 2016; Ahluwalia, 2008; and Abbot, 2007). So that the organizations, buildings and maintenance managers must have knowledge in monitoring the condition of their buildings to prevent defects and failure of the buildings.

Building condition assessment is growing in the context of Asset Management in Malaysia. It becomes important as a tool to improve the current process of building inspection especially to respond to the challenges in managing the buildings. In Malaysia, BCA has been developed according to the requirement of Government Total Asset Management. As in Standard Guideline Condition Assessment for Existing Building (JKR 21602-0004-13, 2013), a condition assessment is performed primarily to facilitate the ranking of all components of the building according to the amount of needed repair and to produce consistent and relevant information. For this study, BCA system developed by Government (JKR 21602-0004-13, 2013) was adopted to analyse the content analysis of the PWD's reports.

\section{METHODOLOGY}

This research is designed to establish a significant relationship between the factors and building condition. The study area for this research was involved for a total number 300 school buildings in Malaysia (Directory of Federal Government Premises Registration, (JKR21600-0012-12), 2011). The sampling criteria used are based on their age, instructional level, and location. The school age is range 11 to 20 years. The reason the school buildings selected to use in this study because the school and educational buildings was the highest total number of building owned by government (MySPATA, 2011), the school building audited were in poor condition (Ali, 2011), school maintenance is still practiced at an unsatisfactory level and increase the cost of maintenance (Yong, 2015). Meanwhile According to Mydin et al. (2014), reported that there are numerous defects most arise and being reported officially by mass media is educational buildings.

Nur Liyana Othman et al (2015) conducted the research based on secondary data by analysing all related document to find out the building defects. So this study and based on secondary data was adopted. The document from the current building inspection report that was kept by PWD which is the report of PWD, Building Condition Inspection for Existing Building report and PWD Building Condition Management Assessment System report. All the defects of the school building can be obtained in this report. The content of all reports has been analysed to identify factors contribute to the defects and assessing the extent of defects of the building. A semi structure interview was conducted to agree that the common factors contribute to the defects especially for building in Malaysia. The factors identified have been analysed using relative index (RII) and rank based on the frequencies. The factors affecting the defects in the buildings to be scored on a five-point Likert Scale based on their significant. The scale for rating the factors are 5 for very high, 4 for high, 3 for average, 2 for low and 1 for very low. The variables identified from the study were tested using both descriptive and inferential statistics. Findings results will be further analysed using correlation analysis using analytical software "IBM SPSS (Statistical Package for the Social Sciences) version 23. Finally, the findings and analysis are tied-up as the conclusion of the research. 


\section{FINDINGS AND DISCUSSIONS}

This session presents the summary of the research work undertaken. The conclusion is drawn from the findings. The findings of the study as follows:-

\subsection{The Factors Contribute to Building Defects}

Based on the research, a total of 40 factors from table 1 were found in the literature which caused the building defect. The factors have been arranged accordingly to similarities to be 29 number of factors to be adopted in this study. In order to adopt the 29 number of factors used in this study, a semi structure interview with an expert of PWD was conducted to confirm and agree that those factors are the common factors contribute to the defects especially for building in Malaysia. These factors will be used in the data collection for the study as shown in table 2. The factors affecting the defects in the buildings scored on a five-point Likert Scale based on their significant.

Table 2: Factors Causes of Building Defects

\begin{tabular}{|c|c|c|c|}
\hline No. & Factors & & Factors \\
\hline 1 & Design & 16 & Ventilation \\
\hline 2 & Detailing & 17 & Thermal Agent \\
\hline 3 & Drawing & 18 & Moisture \\
\hline 4 & Specification & 19 & Chemical Agent \\
\hline 5 & Structural & 20 & Soil impact \\
\hline 6 & Waterproofing & 21 & User \\
\hline 7 & Material & 22 & Vandalism \\
\hline 8 & Maintenance & 23 & Wear and Tear \\
\hline 9 & Construction & 24 & Usage \\
\hline 10 & Building Size & 25 & Workmanship \\
\hline 11 & Type of building & 26 & Lack of Supervision \\
\hline 12 & Building Elevation & 27 & Lack of Knowledge \\
\hline 13 & Insect & 28 & Operation \\
\hline 14 & Biological Agent & 29 & Cleaning \\
\hline 15 & Climatic Condition & & \\
\hline
\end{tabular}

First data was run for reliability analysis for internal consistency measure. Table 3 shows the alpha coefficient for the 21 variables is 0.727 , have acceptable internal consistency. According to research by Mohsen (2011), most of the acceptance value for alpha ranging 0.70 to 0.95 .

Table 3: Alpha Value for Variable Consistency

\begin{tabular}{ccc}
\hline & \multicolumn{3}{c}{ Reliability Statistics } \\
\hline Cronbach's Alpha & Cronbach's Alpha Based on & N of Items \\
& Standardized Items & \\
$\mathbf{7 2 7}$ & $\mathbf{. 7 2 9}$ & $\mathbf{2 1}$ \\
\hline
\end{tabular}

From the analysis, it found that from 29 number of factors analysed and only 21 factors were rank according to the RII reading for most significant factors contribute to defects. For the factors such as detailing, drawing, specification, structural, building size, building types, building elevation, lack of knowledge, and operation has zero variance and is removed from the scale. 
Table 4 shows that the rank of factors contributes to the building defects. The result shows a lack of supervision as the most significant factor with the value of RII 0.919. According to Waziri (2016), quoted the studies by Assaf, Al-Hammad, and Al - Shihah, (1996), and Okuntade (2014), lack of supervision will increase the construction defects and lead to high maintenance during operation. Maintenance factor shows the second highest rank with a value of RII 0.850 from all factors contribute to the defect. The finding is consistent with findings of past studies by (Wardhana, 2003; Chew, 2004; Constantinos, 2005; and Ulang, 2014). Research by Mydin et al. (2014) reported that most of the schools do not practice proper maintenance but carry out emergency maintenance when necessary. So improper practice of maintenance will lead to building defects. Meanwhile, Bagdiya (2015), concluded that the lack of maintenance can reduce the effective life of material and building itself.

The third factor followed by vandalism and material factors with RII values 0.729 and 0.642 .Vandalism is the actions that can damage the school facilities and infrastructure (Mydin et al, 2014). One of improper design factors is a selection of materials (Nur Liyana et al, 2015). According to Chew (2005) reported that selection of material is most important to control building defects. The others factors with less significant values of RII are workmanship with value 0.621. Construction project suffered from the low quality of workmanship and most significant factor contribute to workmanship is a lack of experience (Ali, 2013). Poor workmanship is one of the factors that lead to building defects (Ahzahar et al, 2011). For wear and tear factors with value 0.601, construction with RII value 0.575 , moisture with RII value 0.575 .

The others factors with less significant values below 0.500 are user factor with RII value of 0.470 , climatic condition with value 0.452 , a biological agent with value 0.438 , waterproofing with value 0.423 and insect attack with value of 0.325 . Meanwhile for factors which has the RII value less than 0.300 such as soil impact, cleaning, chemical agent, design, usage, thermal agent, structural and specification.

Table 4: Ranking of Factors Contribute to Building Defects

\begin{tabular}{cccc}
\hline NO & FACTOR & RII & RANK \\
\hline $\mathbf{1}$ & Lack of Supervision & 0.919 & 1 \\
\hline $\mathbf{2}$ & Maintenance & 0.850 & 2 \\
\hline $\mathbf{3}$ & Vandalism & 0.729 & 3 \\
\hline $\mathbf{4}$ & Material & 0.642 & 4 \\
\hline $\mathbf{5}$ & Workmanship & 0.621 & 5 \\
\hline $\mathbf{6}$ & Wear \& Tear & 0.601 & 6 \\
\hline $\mathbf{7}$ & Construction & 0.575 & 7 \\
\hline $\mathbf{8}$ & Moisture & 0.575 & 7 \\
\hline $\mathbf{9}$ & User & 0.470 & 8 \\
\hline $\mathbf{1 0}$ & Climatic Condition & 0.452 & 9 \\
\hline $\mathbf{1 1}$ & Biological Agent & 0.438 & 10 \\
\hline $\mathbf{1 2}$ & Waterproofing & 0.423 & 11 \\
\hline $\mathbf{1 3}$ & Insect Attack & 0.325 & 12 \\
\hline $\mathbf{1 4}$ & Soil Impact & 0.251 & 13 \\
\hline $\mathbf{1 5}$ & Cleaning & 0.189 & 14 \\
\hline $\mathbf{1 6}$ & Chemical Agent & 0.127 & 15 \\
\hline $\mathbf{1 7}$ & Design & 0.067 & 16 \\
\hline $\mathbf{1 8}$ & Usage & 0.054 & 17 \\
\hline $\mathbf{1 9}$ & Structural & 0.043 & 18 \\
\hline $\mathbf{2 0}$ & Thermal Agent & 0.005 & 19 \\
\hline $\mathbf{2 1}$ & Specification & 0.002 & 20 \\
\hline & & & \\
\hline & & & 16 \\
\hline
\end{tabular}




\subsection{Building condition of School Buildings}

Based on the analysis of the secondary data from the PWD report, result shown that 16 schools in good condition with a rating B (6 to 10) which is school building in Kedah, Pulau Pinang, Perak, Selangor, Johor, Terengganu, and Kelantan. 218 school in average condition with a rating C (11 to 15). Terengganu is highest state have a school building with condition C. 65 schools in critical condition with a rating D (16 to 20) and only 1 school in very critical condition with rating E (21 to 25). Table 5 shows the overall condition rating of the school building.

Table 5: Overall Building Condition of School Building

\begin{tabular}{|c|c|c|c|c|c|c|c|}
\hline \multirow[t]{3}{*}{$\mathrm{NO}$} & \multirow[t]{3}{*}{ STATE } & \multirow{3}{*}{$\begin{array}{c}\text { TOTAL } \\
\text { SCHOOL }\end{array}$} & \multicolumn{5}{|c|}{ CONDITION RATING } \\
\hline & & & $\mathbf{A}$ & B & C & D & $\mathbf{E}$ \\
\hline & & & $0-5$ & $6-10$ & $11-15$ & $16-20$ & $21-25$ \\
\hline 1 & Perlis & 4 & 0 & 0 & 1 & 2 & 1 \\
\hline 2 & Kedah & 16 & 0 & 2 & 7 & 7 & 0 \\
\hline 3 & Pulau Pinang & 30 & 0 & 2 & 18 & 10 & 0 \\
\hline 4 & Perak & 32 & 0 & 3 & 21 & 8 & 0 \\
\hline 5 & Selangor & 30 & 0 & 1 & 20 & 9 & 0 \\
\hline 6 & Negeri Sembilan & 21 & 0 & 0 & 14 & 7 & 0 \\
\hline 7 & Melaka & 2 & 0 & 0 & 2 & 0 & 0 \\
\hline 8 & Johor & 27 & 0 & 1 & 17 & 9 & 0 \\
\hline 9 & Pahang & 41 & 0 & 0 & 33 & 8 & 0 \\
\hline 10 & Terengganu & 71 & 0 & 3 & 64 & 4 & 0 \\
\hline 11 & Kelantan & 26 & 0 & 4 & 21 & 1 & 0 \\
\hline & Total & 300 & $\mathbf{0}$ & 16 & 218 & 65 & 1 \\
\hline
\end{tabular}

\subsection{Establish significant relationship between factors and building condition}

This research is designed to establish a significant relationship between the factors and building condition. Twenty-nine (29) variables identified from the research objective and building condition rating as dependent variables. The correlation test using Spearman rank correlation coefficient were used to check the significance relationship between factors and building condition. Correlation is a statistical technique that is useful to determine if there exists a linear relationship between two variables. It is also a useful tool to show how strong or significant is the relationship between the variables. The correlation coefficient or " $r$ " is normally used to measure the strength of the relationship and reported in a value between -1 to +1 . A correlation coefficient, $r$ value close to -1 or +1 showed a strong relationship between the two variables. The $r$ value close to 0 indicates little or no relationship between the two variables. Furthermore, when the correlation is positive or "r" value positive, it shows that the two variables are increasing in the same direction and vice versa for negative $r$ value or inverse correlation.

Further analysis is done to determine the relationship between the overall building conditions rating and the various factors that contribute to the building deterioration. For a model with dependent variable condition rating, the following variables are constants or have missing correlations: detailing, drawing, building size, building types, building elevation, ventilation, lack of knowledge and operation. They will be deleted from the analysis and only twenty-one (21) of variables will be used as a sample in the analysis.

Table 6 shows the ranking of the relationship between defects factors and building condition. From the results, it found that only 7 factors contribute a significant relationship with significant value $\mathrm{p}<0.05$ with building condition of the school building. There appears to be a positive and negative correlation between two variables. Four (4) factors have positive correlation relationship which is maintenance, waterproofing, vandalism and lack of supervision and (3) factors have negative correlation relationship are cleaning, user and a chemical agent. 
Table 6: Ranking of Relationship between Factors Contribute To Building Defect and Building Condition

\begin{tabular}{|c|c|}
\hline FACTORS & CONDITION RATING \\
\hline Maintenance & $.346^{* *}$ \\
\hline Waterproofing & $.247^{* * *}$ \\
\hline Vandalism & $.245^{* *}$ \\
\hline Lack of Supervision & $.212^{* *}$ \\
\hline Cleaning & $-.186^{* * *}$ \\
\hline User & $-.163^{* *}$ \\
\hline Chemical Agent & $-.135^{*}$ \\
\hline Material & .100 \\
\hline Workmanship & .057 \\
\hline Moisture & .051 \\
\hline Insect Attack & .031 \\
\hline Construction & .007 \\
\hline Biological Agent & -.101 \\
\hline Climatic Condition & -.090 \\
\hline Structural & -.071 \\
\hline Thermal Agent & -.058 \\
\hline Specification & -.056 \\
\hline Soil Impact & -.050 \\
\hline Usage & -.042 \\
\hline Design & -.012 \\
\hline Wear and Tear & -.005 \\
\hline
\end{tabular}

Maintenance shows the value of 0.346 which is highest significant a relationship to the building condition. The important factor lead to building defect is maintenance (Talib, 2014). Maintenance has positive correlation which mean if lack of maintenance is most highly factors contribute to building defects, the condition of the building also highly deteriorate. If the maintenance work carried out comprehensively, the condition rating also increase to better condition. According to Syamilah (2005), maintenance of school building usually neglected and influencing the physical condition of the buildings. Ahzahar et al. (2011), stated that maintenance plays a major role in preventing building defects and pointed that the building which is neglect for maintenance may fall into several defects and lead to the structural failures, future financial burden, pose legal and etc. It is important that buildings continue to be properly maintained to ensure that they can function as efficiency and effectively as possible (Ahzahar et al. 2011).

Waterproofing factors have a significant relationship to the building condition with a value of 0.247. According to Suffian (2013), one of the common problems of building defect in the building is due to waterproofing factors which lead to the leakage, cracks, soil settlement, and wall finishes problem. Waterproofing factors will caused to defect such as water leak, tilt, algae / fungus attack, mould, and mildew growth to the element of the building. The problem involving waterproofing always occurred at basement, flat roof, floor at toilet and also walls. And it is the main contributor to the failure of the building that leads to the moisture problems (Othman, 2015). Due to this problem, the condition of the building will deteriorate and will increase the cost of maintenance.

The third important factors are vandalism factors. Vandalism at school potentially could damage the system, and the element of the building (Mydin, 2014). According to Chong and Low (2006), in their research, stated that softer building material often invites vandalism and lead to defects such as cracks, holes, and etc which affect the building condition. It is can be concluded that without proper monitoring from school management on the vandalism issues will affect the building condition of a school building.

According to Ali (2011), lack of supervision in term of monitoring work during construction and maintenance will lead to poor workmanship and affect the building condition. According to Ahzahar et al, (2011), site supervision has a major influence on the overall performance of the building and also reported that supervisors 
have an important role in minimizing the defects in construction. Poor workmanship also due to negligence and inadequate quality control during the execution of construction work either during or post construction especially during rectifying, replacement or maintenance work. Without proper monitoring on the supervision work will lead to the building defects and affect the condition rating of the buildings.

Meanwhile three (3) factors such as cleaning, user and chemical agent have a negative correlation with building conditions. The condition of the building will increase to a better condition when the user aware to clean, use and operate their buildings accordingly with a proper maintenance. Although the other factors are expected to have a relationship with building condition, but according to the (PWD, Building Condition Management Assessment System, 2010) inspection report, not all the factors contribute same defects for each school assessed and not all the factors found affected the building condition of the school. The defect is generated from the various factor based on the type of defects found at the element of the building. They are varies depending on the types of school, location of the school and the size and number of defects found for school.

\section{CONCLUSION}

This paper studied to indicate the scenario of school building condition problem in Malaysia. This paper revealed the significant factors contribute to the building defects which can affect the condition of building in Malaysia. As conclusion, the condition of school building is influenced by the following factors: (i) maintenance; (ii) waterproofing; (iii) vandalism; (iv) lack of supervision; (v) cleaning; (vi) user; (vii) chemical agent; (viii) material; (ix) workmanship; (x) moisture; (xi) insect attack; (xii) construction; (xiii) biological agent; (xiv) climatic condition; (xv) structural; (xvi) thermal agent; (xvii) specification; (xviii) soil impact; (xix) usage; (xx) design; (xxi) wear and tear.

Maintenance shows a highest significant relationship to the building condition. Lack of maintenance influenced the physical condition of the building and also reflect the cost of building maintenance. So in order to ensure the better condition of school building in Malaysia, the comprehensive building condition assessment should be implemented. It is important to identify all the factors contribute to the defects through building condition assessment to evaluate the physical condition of the building, list deficiencies existing in the building, assessed the useful life of the building components for the development a long term capital planning such as renewal / repair / replacement and maintenance planning. The building condition assessment are the most intelligent way to increase the building portfolio's life and at the same time reduce repair and maintenance cost.

\section{REFERENCES}

Addleson, L. (1977). Techincal Study 3 Diagnosis: principles and procedures (AJ Guide to Building Failurse). Architects' Journals, 415-419.

Ahluwalia, S. S. (2008). A Framework for Efficient Condition Assessment of the Building Infrastructure. Canada: University of Waterloo.

Ahzahar, N. (2011). A Study of Contribution Factors to Building Failures and Defects in Construction Industry. Procedia Engineering, 249-255.

Assaf, S., Al Hammad, A. M., \& Al - Shihah, M. (1996). Effect of faulty Desin and Construction on Building Maintenance. Journal of Performance Construction and Facilities, 171-174.

Awol, A. (2016). Assessment on Causes of Defect and the Maintenance Management Practices on Low Cost Building (A Case Study of Jimma Town Condominium). International Journal of Engineering and Technical Research, 151-156.

Badawi, A. A. (2007). Retrieved from http://www.hot-screensaver.com/2006/02/20/billions-wasted-in-repairingpublic-buildings-and-amenities

Chew, M. (2004). Maintainability of Wet Area of Non Residential Building. Sturctural Survey, 39-52. 
Chong, W. K., \& Low, S. P. (2005). Assessment of Defects at Construction and Occupancy Stages. Journal of Performance of Constructed Facilities, 283-289.

Constantinos, A. B. (2005). Deterioration of European Apartment Buildings. Energy and Buildings, 515-527.

DFES. (1993). Assessment Management Plans-Condition Assessments, secyion3a: getting into the condition. Retrieved from http://www.dfes.gov.uk/schoolbuildings.

Hermawan, F. (2013). Toward Sustainable Practice in Building Project at Indonesian Local government: A Case Study of Construction Failure and Building Failure (Defects) in Central Java Indonesia. Proceeding the 6th Civil Engineering Conference in Asia Region: Embracing the Future Through Sustainability, (pp. 2633). Jakarta, Indonesia.

INGENIUM. (2006). International Infrastructure Management Manual. New Zealand: Public Work Engineering of Australia.

Kaiser, H. H. (1993). A Foundation to uphold: A Study of Facilities Conditions at U.S College and Universities, the association of Physical Plant Administrators. Alexandria, Virginia.

Md Ulang, N. (2014). The Impact of Materials and Maintenance Considerations During the Design Stage of Public Buildings in Oman. SHS Web of Conferences (pp. 1-6). EDP Sciences.

Mohd Isa, H. (2011). Learning form of Defects in Design and Build Hospital Projects in Malaysia. International Conference on Social Science and Humanity (pp. 238-242). Singapore: IACSIT Press.

Mohsen, T. (2011). Making Sense of Cronbach's Alpha. International Journal of Medical Education, 53-55.

Okuntade, T. F. (2014). Effects of Faulty Design and Construction on Building Maintenance. International Journal of Technology Enhancements and Emerging Research, 59-64.

Olagunju, R. E. (2012). Predictive Modelling for Sustainable Residential Building Maintenance in Developing Countries: A Nigeria Case. Interdisciplinary Journal of Contemporary Research in Business, 1237-1283.

Othuman, M. (2014). Assessment of Significant Causes to School Building Defects. Emerging Technology for Sustainable Development Congress (ETSDC) (pp. 1-7). EDP Sciences.

PWD. (2010). Building Condition Management Assessment System. Kuala Lumpur: Malaysia Public Work Department.

PWD. (2013). Building Condition Inspection for Existing Building. Kuala Lumpur: Malaysia Public Work Department.

Ramly, A. (2006). Panduan Kerja-kerja Pemeriksaan Kecacatan Bangunan. Malaysia: Hizi Print Sdn Bhd.

Rugless, J. (1993). Condition Assessment Surveys. Facilities Engineering Journal, 11-13.

Shittu, A. A. (2013). Appraisal of Building Defects Due to Poor Workmanship in Public Building Projects in Minna, Nigeria. Journal of Engineering (IOSRJEN), 30-38.

Straub, A. (2009). Dutch Standard for Condition Assessment of Buildings. Journal of Structural Survey, $233-235$.

Suffian, A. (2013). Some Common Maintenance Problems and Building Defects: Our Experiences. Procedia Engineering, 101-108.

Syamilah, Y. (2005). Maintenance Management System Through Strategic Planning for Public School in Malaysia. Malaysia: UTM.

Talib, R. (2014). Assessment of Factors Affecting Building Maintenance and Defects of Public Buildings in Penang, Malaysia. Journal Scientific Academic Publishing, 48-53. 
Wardhana, K. (2003). Study of Recent Building Failures in the United States. Journal of Performance of Constructed Facilities, 151-158.

Watt, D. (1999). Building Pathology: Principles and Practice. United Kingdom: Blackwell Science, Oxford.

Waziri, B. S. (2016). Design and Construction Defects Influencing Residential Building Maintenance in Nigeria. Jordan Journal of Civil Engineering, 313-323.

Samah, A.H, Tawil N.M, Mahli, M, Che-Ani, A.I and Abd-Razak, M.Z. (2014). Building Condition Assessment Using Condition Survey Protocol Matrix: A Case of School Building. Research Journal of Applied Science 9 (9), 565-572

Bagdiya N.V, Wadalkar S. (2015). Review Paper on Construction Defects. IOSR Journal of Mechanical and Civil Engineering (IOSR-JMCE), 88-91

Allotey S.E. (2014). An Evaluation of the Impact of Defects in Public Residential Building in Ghana. Civil and Environmental Research, 58-64

Mastura, J, Nur Liyana, O. (2015). Categorisation and Causes of Building Design Defect: A Case Study on Public Building Hospital.

Agyekum, K, Ayarkwa, J, Amoah, P. (2016). Built and Forgotten: Unveiling The Defects Associated with The Ghana Cocoa Board (Cocobod) Jubilee House in Kumasi. Journal of Building Performance, 23-34

Nur Liyana, O, Mastura, J, Wan Mariah, W.H, Fuziah, I. (2014). A Case Study on Moisture Problems and Building Defects. Procedia-Social and Behavioral Sciences, 27-36. Seoul, S.Korea

Douglas J. And Ransom B. (2006). Understanding Building Failure. 3rd Taylor and Francis, London: 222-232 